\title{
Current and Emerging Therapies in Multiple Sclerosis: Implications for the Radiologist, Part 2-Surveillance for Treatment Complications and Disease Progression
}

\author{
(D) C. McNamara, DG. Sugrue, (DB. Murray, and DP.J. MacMahon
}

\begin{abstract}
SUMMARY: An understanding of the new generation of MS drugs in conjunction with the key role MR imaging plays in the detection of disease progression, opportunistic infections, and drug-related adverse effects is of vital importance to the neuroradiologist. Part 1 of this review outlined the current treatment options available for MS and examined the mechanisms of action of the various medications. It also covered specific complications associated with each form of therapy. Part 2, in turn deals with the subject of pharmacovigilance and the optimal frequency of MRI monitoring for each individual patient, depending on his or her unique risk profile. Special attention is given to the diagnosing of progressive multifocal leukoencephalopathy in patients treated with natalizumab as this is a key area in which neuroradiologists can contribute to improved patient outcomes. This article also outlines the aims of treatment and reviews the possibility of "no evidence of disease activity" becoming a treatment goal with the availability of more effective therapies. Potential future areas and technologies including image subtraction, brain volume measurement and advanced imaging techniques such as double inversion recovery are also reviewed. It is anticipated that such advancements in this rapidly developing field will improve the accuracy of monitoring an individual patient's response to treatment.
\end{abstract}

ABBREVIATIONS: $\mathrm{BV}=$ brain volume; $\mathrm{DIR}=$ double inversion recovery; $\mathrm{DMT}=$ disease-modifying therapy; IRIS = immune reconstitution inflammatory syndrome; $J C$ virus $=$ John Cunningham virus; $M T R=$ magnetization transfer ratio; NEDA $=$ no evidence of disease activity; $N T Z=$ natalizumab; NTZ PML = natalizumab-associated PML; PML = progressive multifocal leukoencephalopathy; PML IRIS = PML-associated IRIS; PSIR = phase-sensitive inversion recovery

$\mathbf{P}$ art 1 of this review covered recent developments in the treatment of MS and discussed the published clinical data on the efficacy and safety of the currently approved and emerging therapies in this condition as they apply to the radiologist. Part 2 will focus on the role of the radiologist in monitoring patients being treated with these medications and will focus on pharmacovigilance, which includes observation for treatment complications and signs of disease progression.

\section{Frequency of MR Imaging for Drug Monitoring}

MR imaging is recommended before the initiation or modification of disease-modifying therapy (DMT) and approximately 6 months after a treatment switch to allow sufficient time for the new therapy to reach its therapeutic potential. ${ }^{1}$ Therefore, some authors suggest that the reference scan should be obtained no earlier than 3 months after treatment initiation/change to over-

From the Departments of Radiology (C.M., G.S., P.J.M.) and Neurology (B.M.), Mater Misericordiae University Hospital, Dublin, Ireland.

Please address correspondence to Peter MacMahon, MD, Department of Radiology, Whitty Bldg, North Circular Rd, Mater Misericordiae University Hospital, Dublin 7, Ireland; e-mail: pmacmahon@mater.ie; @McnamaraCillian

-- Indicates open access to non-subscribers at www.ajnr.org

http://dx.doi.org/10.3174/ajnr.A5148 come the uncertainty about new lesions occurring before the treatment becomes effective. ${ }^{2}$ Continued or worsening disease activity on MR imaging while a patient is on a DMT may prompt a change in therapy. There is evolving evidence that ongoing MR imaging activity can be indicative of a suboptimal therapeutic response ${ }^{3}$; however, due to variable pharmacodynamics, the time until MR imaging activity is suppressed differs among the immunomodulatory agents. ${ }^{4}$

Several studies have attempted to define criteria and strategies for the early identification of suboptimal response in individual patients via a combination of clinical and MR imaging measures during the first 6-12 months after treatment initiation. ${ }^{5-7}$ These criteria are partially or completely based on the detection of disease activity on follow-up brain MR imaging studies, defined as new gadolinium-enhancing lesions or new and/or enlarging T2 hyperintense lesions. ${ }^{8}$

More frequent surveillance may be indicated in clinically aggressive cases or unusual patterns (eg, tumefactive MS) (Table 1). Clinical judgment and experience are critical in such cases. While guidelines on a tolerable threshold for new lesion activity that warrants a change in therapy have been proposed, individual factors will impact the clinician's decision as to the exact frequency of MR imaging monitoring and time to switch ther- 


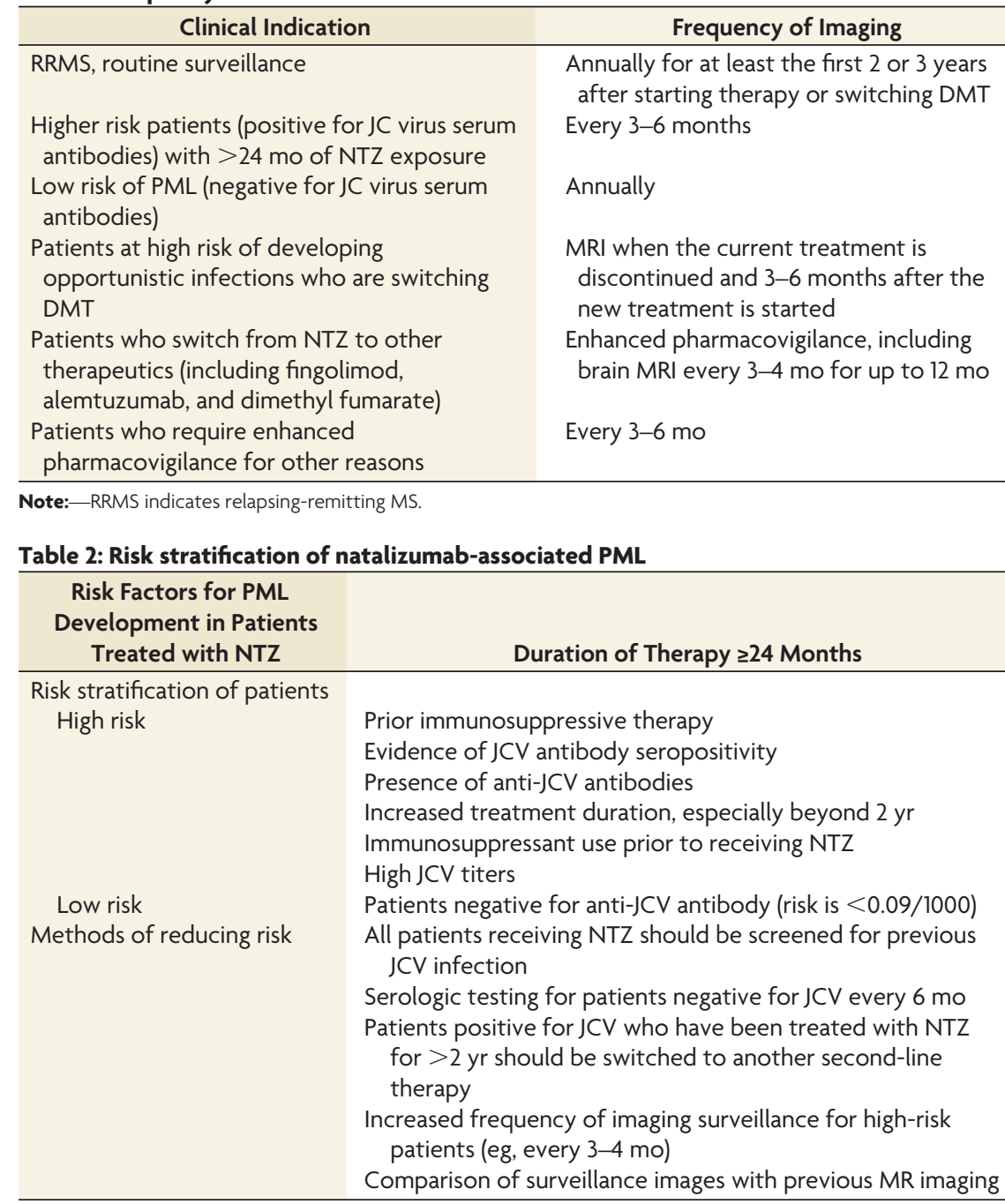

Note:- JCV indicates John Cunningham virus.

apy. ${ }^{1,7,9}$ Isolated worsening on the neurologic examination or brain MR imaging should lead to closer monitoring rather than an immediate switch of therapy; with silent brain MR imaging activity, reassessing the MR imaging in several months is recommended. ${ }^{10}$

\section{Imaging Surveillance for Opportunistic Infections}

Particularly high-risk patients (natalizumab [NTZ] treatment longer than 24 months, serology positive for John Cunningham [JC] virus serology, prior immunosuppression) should be screened every 3-6 months with at least a curtailed MR imaging protocol to include FLAIR, T2-weighted, DWI, and SWI sequences if available. ${ }^{8}$ Low-risk patients (JC virus seronegative) can be imaged on an annual basis (Table 2). ${ }^{8,11}$ MR imagingbased monitoring of patients for early progressive multifocal leukoencephalopathy (PML) detection is not recommended for those patients treated with NTZ exclusively, but also for patients being treated with other DMTs, including alemtuzumab, fingolimod, and dimethyl fumarate. ${ }^{12,13}$ In addition, PML is not the only opportunistic infection that can be observed during MS treatment. MS treatment-related infections include a wide-ranging spectrum of pathogens such as varicella zoster virus, as has been described in patients treated with fingolimod. ${ }^{14}$

There is now growing evidence that drug-related adverse effects can occur when MS medication is discontinued or even several months after a new treatment is started (so-called "carry over opportunistic infections"). Therefore, strict pharmacovigilance, including frequent MR imaging, should be performed in patients who switch therapies, to detect resurgent MS disease activity and adverse effects such as opportunistic infections. ${ }^{15-17}$ In patients at high risk of developing opportunistic infections (eg, immunocompromised patients, those recently treated with a course of immunosuppressants) who are switching DMTs, brain MR imaging is recommended when the current treatment is discontinued and after the new treatment is started. Thus, heightened pharmacovigilance, including brain MR imaging every 3-4 months for up to 12 months, is required in patients who switch from NTZ to other medications (such as fingolimod, alemtuzumab, and dimethyl fumarate). ${ }^{8}$ To date, among patients switching to fingolimod treatment after previous natalizumab therapy, there have been 17 suspected cases of PML. ${ }^{18}$

\section{Diagnosing PML}

Although differentiating between a new MS lesion and an evolving PML lesion can be challenging, radiologists must be familiar with the key imaging features associated with PML because a timely and accurate diagnosis at the asymptomatic stage is associated with improved survival and functional outcome compared with patients identified at the symptomatic stage. ${ }^{19} \mathrm{MR}$ imaging has been shown to be sensitive in the detection of PML lesions and can identify such lesions several months before the onset of clinical symptoms. ${ }^{20}$

The current diagnostic criteria for PML as established by the American Academy of Neurology include the presence of 3 components: a clinical picture suggestive of PML (eg, behavioral and 
Table 3: MRI Features of PML

\begin{tabular}{ll}
\hline \multicolumn{1}{c}{ Features } & \\
\hline Location & Subcortical white matter U-fibers \\
Size & Predilection for frontal lobe $>$ occipital lobe $>$ parietal lobe \\
& Small, $<3 \mathrm{~cm}$ when asymptomatic \\
Morphology & In symptomatic patients, lesions are often large $(>3 \mathrm{~cm})$ \\
& $\begin{array}{l}\text { Punctate lesions often identified in asymptomatic PML } \\
\text { Symptomatic PML typically demonstrates more confluent and } \\
\text { diffuse lesions } \\
\text { Microcysts }\end{array}$ \\
& No associated edema or mass effect \\
TIWI and T2WI & FLAIR hyperintensity with corresponding TI hypointense lesions \\
& TI hypointesity is less pronounced in asymptomatic PML \\
DWI & Hyperintensity on DWI \\
TI postcontrast & 30\% will demonstrate linear or punctate enhancing lesions; if \\
& nodular or rim enhancement is present, active MS plaque or \\
IRIS should be considered & Low signal intensity in U-fibers \\
Differential diagnosis & MS plaque \\
& Acute disseminated encephalomyelitis \\
& Tumefactive lesion \\
Ischemic changes \\
Posterior reversible encephalopathy syndrome
\end{tabular}

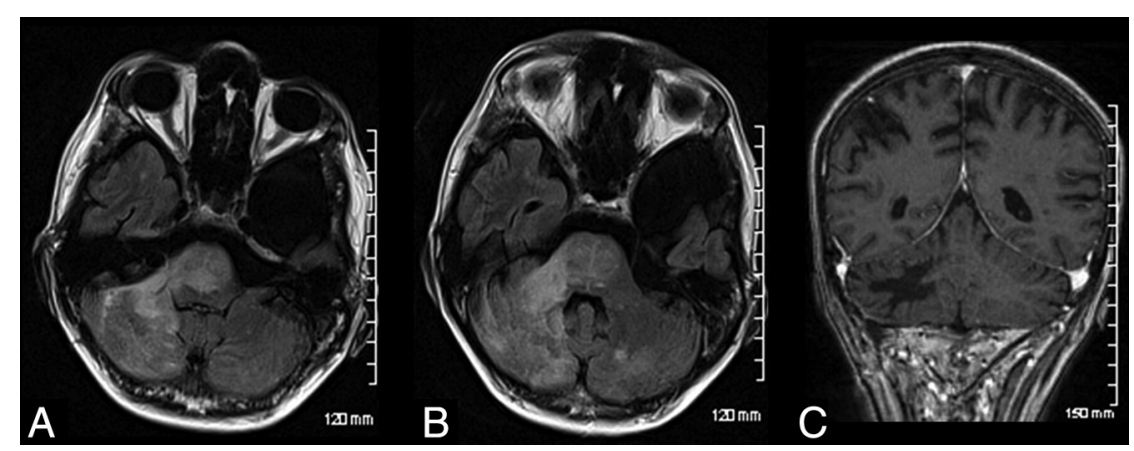

FIG 1. Infratentorial natalizumab-associated PML. Axial FLAIR ( $A$ and $B$ ) images of a patient demonstrating extensive hyperintense signal involving the cerebellum, middle cerebellar peduncle, and pons. This had progressed from prior imaging. Note minimal mass effect. Postadministration of gadolinium, there is no enhancement demonstrated $(C)$.

cognitive abnormalities, progressive weakness, gait abnormalities, visual field deficits, speech and language disturbances, and/or incoordination), biochemical and/or histologic evidence of the JC virus, and MR imaging findings. ${ }^{21}$ Compared with symptomatic PML, in which the lesion dissemination typically involves multiple lobes affecting both hemispheres, patients with asymptomatic PML present more frequently with a localized disease in a unilobar and focal distribution. ${ }^{19,20}$ Most interesting, compared with other PML cohorts, contrast enhancement can be observed quite frequently in natalizumab-associated PML (NTZ PML), occurring in approximately $30 \%$ of all patients at diagnosis, and can be the leading radiologic sign in asymptomatic patients. ${ }^{22-24}$

Substantial evidence indicates that FLAIR is the most sensitive sequence for detecting PML. ${ }^{22}$ DWI is known to be highly sensitive for depicting acute demyelination but can also aid in the differentiation of acute PML lesions from chronic and subacute demyelinating MS lesions. ${ }^{22}$ In patients with MR imaging lesions suggestive of PML, the MR imaging protocol should be extended to include pre- and postcontrast T1-weighted imaging to detect inflammatory features and the possible coincidence of PML and
PML-immune reconstitution inflammatory syndrome, particularly during MS follow-up imaging. ${ }^{25,26}$

The most common area to be affected by NTZ PML is the frontal lobe, followed in frequency by the occipital lobe and then the parietal lobe (Table 3). ${ }^{27,28}$ Like other aggressive infiltrating lesions, PML can also infiltrate the corpus callosum, though isolated corpus callosal involvement is rare. ${ }^{29}$ PML lesions occur in the posterior fossa in early PML in approximately $10 \%$ of cases at initial presentation (Fig 1). ${ }^{28}$ These most commonly involve the cerebellum and middle cerebellar peduncles, though the brain stem can be affected. ${ }^{27,30}$ Crescent-shaped lesions involving the middle cerebellar peduncles and adjacent cerebellar and/or pontine white matter may be specific to PML, rather than MS, because they have, so far, only been reported in patients with PML. ${ }^{30-32}$ Deep gray matter (including the thalamus and dentate nuclei) PML lesions are unusual (5\%) in NTZ PML, particularly in the early disease course. ${ }^{22}$

A 2016 study published in Radiology by Hodel et $\mathrm{al}^{27}$ investigated the radiologic findings of NTZ PML at the asymptomatic stage. They concluded that hyperintensity on DWI and involvement of U-fibers were the most predictive MR imaging features for the diagnosis of asymptomatic NTZ PML. Their results also suggested that punctate lesions may be a highly specific finding for NTZ PML, being exclusively observed in patients with NTZ PML. Most of the lesions observed in their study involved the frontal lobe as has been previously reported in other studies. ${ }^{28}$ They also found that comparison of the patient's current MR images with those from previous MR imaging examinations significantly improved the specificity for the detection of NTZ PML lesions and for the diagnosis of PML (from 88\% without to $100 \%$ with previous MR imaging; $P=.05$ ). Recent evidence also suggests that SWI may be of value in the early diagnosis of PML (Fig 2). In particular, low signal intensity observed in U-fibers identified with SWI has been reported as a unique finding in early PML. ${ }^{33,34}$ Most interesting, the rate of PML in patients treated for $<1$ year remains virtually zero. Thus, the patient's length of treatment with natalizumab should be provided to the radiologist when interpreting MR imaging findings.

\section{PML-Immune Reconstitution Inflammatory Syndrome}

In a bid to halt the progression of PML, plasma exchange or immunoadsorption can be used to remove NTZ from the circulation, which allows lymphocytes to cross the BBB once again. ${ }^{35}$ 


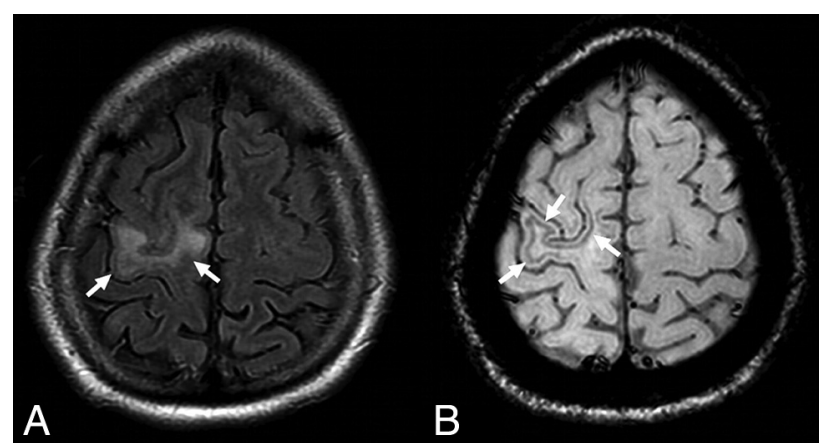

FIG 2. A typical example of natalizumab-associated PML. There is a FLAIR hyperintense lesion involving the right precentral gyrus ( $A$, arrows) abutting the cortex. The susceptibility-weighted sequence reveals a hypointense rim involving the subcortical U-fibers adjacent to the PML lesion ( $B$, arrows). Reprinted from Hodel et al. ${ }^{34}$

This sudden restoration of cellular immunity can paradoxically result in the worsening of the patient's neurologic status with the development of immune reconstitution inflammatory syndrome (IRIS). ${ }^{36}$ The development of IRIS occurs days to weeks following treatment with plasma exchange or immunoadsorption. ${ }^{35,36}$ PML-associated IRIS (PML IRIS) can, however, also occur following the cessation of NTZ alone without plasma exchange. ${ }^{26}$ In such cases, immunologic rebound with IRIS takes approximately 3 months postcessation, in keeping with the long half-life of the drug. ${ }^{37}$ This represents a challenge for the radiologist because neurologic dysfunction and white matter lesions occurring after NTZ interruption may also be caused by MS exacerbations. ${ }^{38}$ The literature suggests that PML IRIS tends to occur first in such cases followed by recurrences of MS activity at later follow-up imaging, suggesting that timing is key to reaching a diagnosis. ${ }^{17,25,28}$

Imaging findings that can assist in the diagnosis of PML IRIS include contrast enhancement and rapid progression of existing PML lesions, which begin to exert mass effect through swelling and edema. ${ }^{37,39,40}$ Current data, though limited, suggest that contrast enhancement with either a patchy or punctate pattern in the border of the PML lesion is the most frequent imaging sign in early PML IRIS (Fig 3). ${ }^{39}$ Gheuens et $\mathrm{al}^{41}$ have developed a diagnostic model using proton MR spectroscopy to help differentiate PML IRIS lesions from lesions without IRIS on the basis of their metabolic profile and the presence contrast enhancement.

\section{Assessing Radiologic Response to Therapy}

Several studies have demonstrated that the occurrence of new T2 lesions or gadolinium-enhancing lesions during the first year of a treatment (most studies have investigated treatment with interferon $\beta$ ) correlates with progression of disability. ${ }^{42,43}$ These 2 measures have relevant differences. While contrast-enhancing lesions are considered a marker of acute inflammation in patients with MS, new T2 hyperintense lesions reflect the permanent footprint from a previous focal inflammatory lesion that developed in the interval between 2 scans. ${ }^{44}$

Determining ongoing radiologic stability is based on the presence or absence of new lesions (whether T2-weighted or contrastenhancing lesions)..$^{5,42,43,45,46}$ In a large retrospective study of patients with MS on therapy, the presence of $>2$ contrast-enhancing lesions at 1 year was predictive of poor clinical outcome at 5

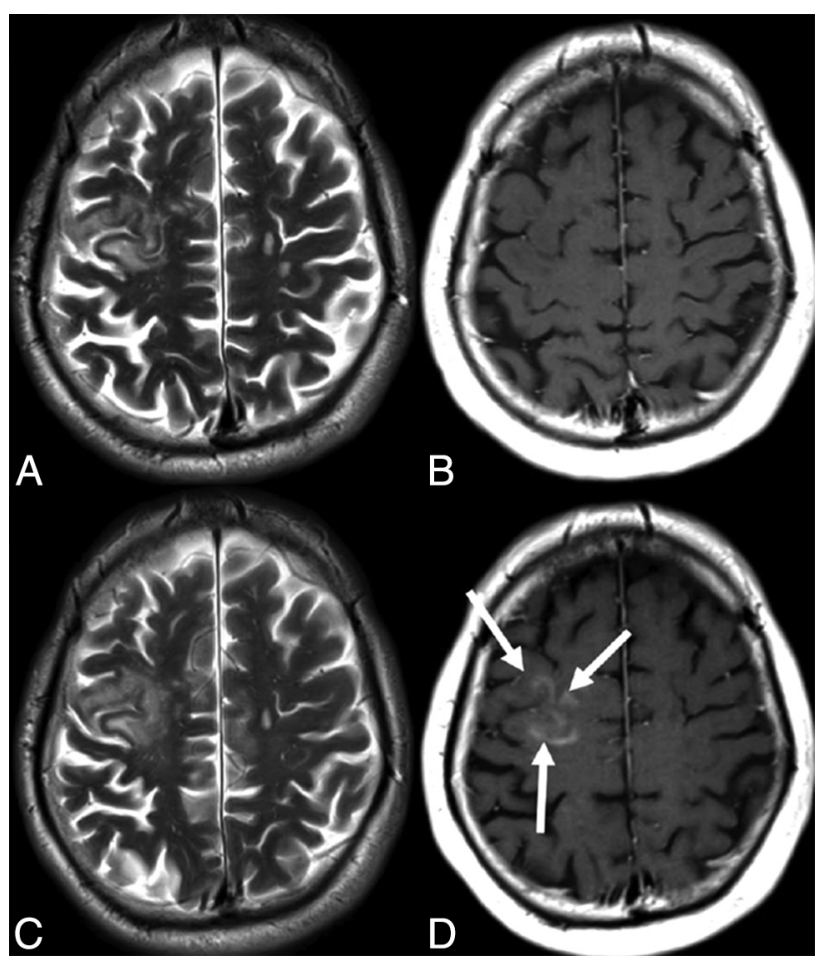

FIG 3. Axial T2-weighted and contrast-enhanced T1-weighted images showing imaging signs suggestive of natalizumab-associated PML ( $A$ and $B$ ) with follow-up imaging post-withdrawal of medication suggestive of PML-immune reconstitution inflammatory syndrome. This patient demonstrates the most frequent pattern of PML IRIS, with patchy contrast enhancement in the border of the lesion (arrows). Reproduced from Wattjes et $\mathrm{al}^{39}$ with permission from BMJ Publishing Group Ltd.

years. ${ }^{47}$ The Barcelona and Cleveland Clinic groups have both shown that the accumulation of a certain number of new T2 lesions, with or without clinical relapse, has a predictive value for disability progression during the next few years. ${ }^{3,43,48}$ For example, Rio et $\mathrm{al}^{49}$ showed that \pm 3 lesions after 1 year of treatment predicted increased disability after 2 years $(\mathrm{OR}=8.3,71 \%$ sensitivity, $71 \%$ specificity).

A scoring system proposed by Rio et al $^{50}$ combines commonly used, short-term (ie, 1-year) treatment measures of disease activity, such as clinical relapses, Expanded Disability Status Scale progression, and active MR imaging lesions, to identify patients at risk of developing new clinical activity (ie, relapses) during the ensuing years. The other novelty provided by this proposed score is the use of the number of new T2 hyperintense MR imaging lesions instead of gadolinium-enhancing lesions. Previous approaches have used gadolinium-enhancing lesions to assess MR imaging activity because they are easier to detect as already mentioned. ${ }^{42,43,51}$ The Rio Criteria or the Modified Rio Criteria are guides to prognosis; but unfortunately, their sensitivity and specificity are not considered accurate enough for routine clinical practice. $^{5,6}$

Critics have dismissed T2 lesions as a predictive biomarker because of the moderate-to-poor short-term correlation between the accumulation of lesions and outcome. However, long-term studies are much more informative. For example, in the Queen Square 21-year clinically isolated syndromes follow-up study, T2 lesion load was highly predictive of a poor clinical outcome. ${ }^{52}$ In a 
meta-analysis from 23 randomized placebo-controlled clinical trials involving 6591 patients, regression models demonstrated that the treatment effect on T2 hyperintense lesions correlated with the effect on relapses. ${ }^{46}$ Most interesting, the development of new T2 lesions in patients with MS on DMT is much more predictive of long-term outcome compared with the development of new T2 lesions in patients on no treatment or a placebo. ${ }^{53-55}$ Such data make a compelling case for suppressing the development of T2 lesions as a treatment target, with the aim of delaying or preventing the onset of secondary-progressive MS. One drawback of such an approach is that the detection of new T2 hyperintense lesions can be challenging, especially if there is a preexisting high load of lesions, and one has to factor in variable positioning on serial scans and $1.5 \mathrm{~T}$-versus-3T lesion detection. ${ }^{56}$

Whereas the classification of new T2 lesions can be more difficult and is more time-consuming, T2 signal alterations are a durable "footprint" of plaque formation and thus a relatively reliable means of ascertaining lesion accumulation. ${ }^{5}$ Some of the limitations of T2 lesion counting could be overcome by technologic innovations, for example emerging registration and subtraction techniques. ${ }^{57}$

\section{Defining "Nonresponders"}

Effective DMT treatment has been shown to be especially beneficial early in the course of MS. Thus, rapid identification of nonresponders is crucial to determine the need for a therapeutic switch. ${ }^{58}$ Patients with MS who continue to experience clinical and/or radiologic disease activity despite treatment with DMT are categorized as "nonresponders." ${ }^{3,48,50}$ The response of patients with MS to DMT is very heterogeneous; thus, it is especially difficult to determine whether a particular treatment of choice is producing the desired effect. ${ }^{48}$ Proposed scoring methods to identify patients with a suboptimal treatment response on the basis of combined clinical and radiologic measures at follow-up have shown considerable variation. ${ }^{8}$ Moreover, such criteria have been developed almost exclusively in patients receiving different formulations of interferon $\beta$. Few data are available from patients undergoing treatment with the newer DMTs in clinical practice. ${ }^{8}$

\section{Advancing toward "No Evidence of Disease Activity"}

With the introduction of new, more effective therapies, there has been a shift in treatment expectations from partial response to potential remission, with no evidence of disease activity (NEDA) being the new treatment target. NEDA is defined as the following: 1) absence of relapses, 2) absence of sustained disability worsening, and 3) absence of radiologic activity, seen as gadoliniumenhancing lesions or new/enlarged T2-hyperintense lesions (NEDA-3). ${ }^{59}$ More recently, this composite outcome has been implemented by also considering the absence of brain volume loss (NEDA-4). ${ }^{60}$ The clinical significance of NEDA in the long-term, however, is still lacking, and the concept is still evolving because there is debate over additional measures that could or should be included, such as loss of brain volume as a marker. ${ }^{61,62}$ Realistically because DMT is only partially effective, some lesion accumulation is an expected outcome for patients treated with these therapies and neurologists do not routinely switch DMTs with minor asymptomatic relapses. ${ }^{61}$ While new T2 lesions during treatment are undesirable, studies are heterogeneous in relation to the number of new lesions considered significant disease activity. In a recent systematic review investigating the role of MR imaging in the assessment of treatment response to interferon $\beta$, pooled data of new T2 lesions did not show statistical significance for those patients with only 1 new T2 lesion per year. ${ }^{63}$ A 2016 study published by Prosperini et $\mathrm{al}^{64}$ showed that $34 \%$ of patients treated with natalizumab achieved NEDA-3 at 7-year follow-up.

From the clinician's point of view, there are multiple justifications for switching therapies. First, MS involves diverse pathologic mechanisms that no single DMT addresses. Second, MS is heterogeneous, and one might expect a given agent to work better in one patient than another. Third and perhaps most important, no DMT actually cures MS. Approximately $30 \%$ of patients show a suboptimal therapeutic response during the early treatment years. ${ }^{65,66}$ Therefore, NEDA may be an unrealistic long-term expectation, especially when economic factors and adverse effects are taken into account. There are no uniform criteria for choosing the initial DMT to be trialed in an individual patient. This decision is guided by drug, disease, and patient considerations; personal preferences and experiences; and economic and availability factors. Most initial treatment choices would involve a first-line agent before consideration is given to a second-line agent such as NTZ.

\section{Future Areas}

Brain Atrophy as a Marker. Numerous studies have used MR imaging-derived methods to assess brain volume (BV) changes in MS, revealing that atrophy can be present even in the early stages of the condition and that it progresses during the disease course. ${ }^{67,68}$ Several MR imaging studies consistently reported associations between whole-brain gray matter loss and increases of lesion load. ${ }^{69,70}$ The clinical relevance of brain atrophy is wellknown: Compared with measures of lesion load, brain atrophy shows better correlations with progression of disability and cognitive impairment, with gray matter atrophy being more closely associated with clinical dysfunction than white matter atrophy. ${ }^{71}$ The overall effect of treatment on brain atrophy can be reflective of the effect of the therapy on disability. ${ }^{55}$ The more recent DMTs have been shown to decrease rates of brain atrophy when compared with a placebo. ${ }^{72}$ Thus, recent clinical trials have incorporated BV outcomes as a measure of treatment effect. ${ }^{73}$ Current methods for measuring BV in radiology are usually automated software that either uses a segmentation-based approach (such as statistical parametric mapping) for cross-sectional data or a registration-based approach (such as structural image evaluation with normalization of atrophy) for longitudinal analysis. ${ }^{72} \mathrm{Un}$ fortunately, the clinical interpretation of BV loss in patients with MS can often be difficult with other confounding factors such as hydration status and ongoing inflammation at the time of treatment onset. ${ }^{74}$ Moreover, differences in the quality and capabilities of MR imaging hardware and in the software packages used for analysis or processing can generate notable variability in brain atrophy assessment. ${ }^{71,75}$

In many trials, DMTs have produced only moderate evidence of a reduction in BV loss. This is because anti-inflammatory agents have been shown to increase the rate of BV reduction 


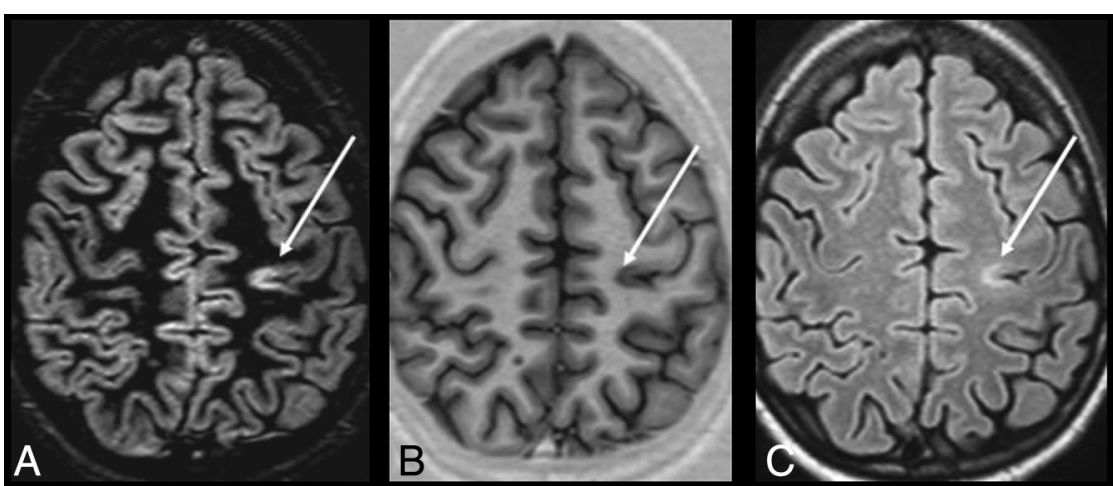

FIG 4. DIR (A), PSIR $(B)$, and FLAIR $(C)$ images from a single patient with $M S$ at the same section location. An intracortical lesion is evident in the left parietal area. Also, note the excellent overall delineation of the gray-white matter border on PSIR. Reprinted from Nelson et al. ${ }^{100}$

within the first 6 months to 1 year of treatment, followed by stabilization during the second year of treatment. ${ }^{76}$ Resolution of this inflammation will lead to an initial accelerated BV loss that has been described as a "pseudoatrophy" effect. ${ }^{73}$ Therefore, the most clinically efficacious drugs (with a high impact on inflammation), such as natalizumab, ${ }^{77-79}$ fingolimod ${ }^{80}$ or high-dose interferon $\beta,{ }^{81}$ will tend to produce larger-than-placebo BV decreases during the first months of therapy, which, at least in part, may not be related to true tissue damage. The difficulties in clinical interpretation of BV loss outlined above such as the pseudoatrophy effect explain why this novel technique is not currently employed in routine clinical use.

Image Subtraction to Detect New Lesions. A second area of growing interest is the accurate detection of active lesions and its achievement. Both new and enlarging lesions, imaged with standard serial nonregistered 2D images, are complicated by repositioning errors and a background of unaltered nonactive lesions. ${ }^{82}$ Subtraction images, after image registration, provide an alternative strategy in which the effect of repositioning errors is reduced, cancelling out radiologically stable disease. In both single-center and multicenter settings, 2D subtraction images depicted higher numbers of active lesions with greater interobserver agreement compared with nonregistered 2D T2-weighted spin-echo images. ${ }^{83,84}$ Image subtraction can overcome issues associated with differentiating old $\mathrm{T} 2$ lesions from new $\mathrm{T} 2$ lesions, thus providing good visualization and quantification of active and resolving lesions. ${ }^{85}$ Recent data have shown that automated identification of new or enlarging $\mathrm{T} 2$ lesions is robust, accurate, and sensitive, thus supporting its use for evaluating treatment efficacy in clinical trials. ${ }^{86}$ Long-interval T2-weighted sequences can be processed with automated subtraction, which has been used in a multicenter trial to provide greater power for assessing treatment efficacy than is possible with monthly contrast-enhanced $\mathrm{T} 1$-weighted imaging. ${ }^{85,87}$ However, subtraction requires time-consuming postprocessing steps, and the process can be susceptible to imaging artifacts.

Advanced Imaging Techniques. A broadening spectrum of emerging MR imaging techniques allows a more specific evaluation of MS pathology. Included in these new methods are the following: magnetization transfer ratio (MTR), diffusion tensor imaging, restricted proton fraction, and positron-emission tomography techniques. ${ }^{4}$ Furthermore, additional pulse sequences such as double inversion recovery (DIR) and phase-sensitive inversion recovery (PSIR) have improved the detection rate of cortical lesions. ${ }^{88,89}$

Although conventional MR imaging is very sensitive to macroscopic lesions, it lacks sensitivity to the microscopic pathology. Diffusion MR imaging techniques, including DTI and diffusional kurtosis imaging, are sensitive to diffuse microscopic injury in the normal-appearing white matter and gray matter of patients with MS. ${ }^{90}$ These techniques provide quantitative parameters such as fractional anisotropy and mean diffusivity, which correlate well with tissue damage that is not visible on T2 and FLAIR imaging. ${ }^{91}$ DTI may also assist in evaluating the structural integrity of white matter and can be used for probabilistic or deterministic tractography. ${ }^{92}$ In one in vivo study of MS, radial diffusivity appeared to provide the closest correlation with tissue integrity. ${ }^{93} \mathrm{~A}$ multicenter validation study indicated that fractional anisotropy was the most comparable DTI measure across centers and endorsed its use in multicenter clinical trials. ${ }^{94}$ Werring et $\mathrm{al}^{95}$ demonstrated that a steady and moderate increase of the apparent diffusion coefficient can precede the development of new plaques by $6-8$ months, and they indicated that structural changes in prelesion normal-appearing white matter occur before inflammation and BBB leakage.

MTR is a technique based on the transfer of magnetization between semisolid and water protons in different structural environments. ${ }^{92}$ Longitudinal studies demonstrate decreases in MTR preceding contrast enhancement. The magnitude of the MTR decline during gadolinium enhancement predicts whether a lesion will evolve into a T1 hypointense one. ${ }^{96}$ Thus, MTR alteration has been proposed as a marker of overall lesion severity. Partial or complete resolution of the MTR may occur as inflammation is reduced and remyelination ensues. ${ }^{97}$ Due to these features, this technique provides a promising primary outcome measure to evaluate remyelinating therapies in clinical trials. Several metrics that have been proposed for further study include intralesional MTR and whole-brain MTR. ${ }^{98}$

DIR sequences simultaneously suppress CSF and white matter signals, thereby increasing the detectability of gray and white matter lesions in MS significantly. ${ }^{99}$ Several reports have shown the utility of DIR and PSIR images for detecting MS plaques, especially in intracortical or mixed white matter-gray matter areas compared with FLAIR and T2-weighted images (Fig 4)..$^{8,100,101}$ Hagiwara et al ${ }^{102}$ recently showed that such sequences could be recreated by using synthetic MR imaging techniques, which lead to greater diagnostic accuracy than conventional MR images in comparable acquisition times.

Last, there have been studies that have combined the above imaging advances with promising results. Calabrese et $\mathrm{al}^{103}$ showed that the combination of DIR and DTI constitutes a substantial step forward in the analysis of cortical disease in MS. They 
combined these techniques to analyze the cortex of patients with relapsing-remitting MS and found that fractional anisotropy was significantly increased in cortical lesions compared with normalappearing gray matter. Their study concluded that there is a high correlation between the fractional anisotropy of normal-appearing gray matter and the progression of physical disability during a 3-year follow-up. Another example is the combined use of DIR and PSIR, which allows more reliable detection of cortical lesions in MS than DIR techniques alone. The addition of PSIR also provides better delineation of lesion boundaries, which results in a more confident classification of lesions as purely intracortical, mixed, or juxtacortical. ${ }^{100}$

Although the use of quantitative MR imaging measures for disease monitoring shows much promise, their use in routine clinical practice is, in part, hindered by the longer acquisition and postprocessing times and a current lack of standardization.

\section{CONCLUSIONS}

The field of MS therapeutics is a rapidly evolving one. For radiologists to provide an informed opinion in discussions of newer MS agents, they must have a working understanding of the strengths and limitations of various novel therapies. The role of imaging in MS has advanced beyond confirmation of disease presence to include the monitoring and surveillance of disease activity and treatment complications. An understanding of the new generation of MS drugs in conjunction with the key role MR imaging plays in the detection of disease progression, opportunistic infections, and drug-related adverse effects is of vital importance to the radiologist and physician alike. Radiologists are in a unique position to detect many of the described complications well in advance of clinical symptoms. This rapidly expanding area will see much change in the years to come, and it is more important than ever for the neurologist and radiologist to work together in the pursuit of improved outcomes for the patient with MS.

\section{ACKNOWLEDGMENTS}

The authors thank Drs Seamus Looby and Ronan P. Killeen for providing images for the article.

\section{REFERENCES}

1. Traboulsee A, Simon JH, Stone L, et al. Revised Recommendations of the Consortium of MS Centers Task Force for a Standardized MRI Protocol and Clinical Guidelines for the Diagnosis and Follow-Up of Multiple Sclerosis. AJNR Am J Neuroradiol 2016;37:394401 CrossRef Medline

2. Stangel M, Penner IK, Kallmann BA, et al. Towards the implementation of 'no evidence of disease activity' in multiple sclerosis treatment: the multiple sclerosis decision model. Ther Adv Neurol Disord 2015;8:3-13 CrossRef Medline

3. Rudick RA, Lee JC, Simon J, et al. Significance of T2 lesions in multiple sclerosis: a 13-year longitudinal study. Ann Neurol 2006; 60:236-42 CrossRef Medline

4. Wattjes MP, Steenwijk MD, Stangel M. MRI in the diagnosis and monitoring of multiple sclerosis: an update. Clin Neuroradiol 2015; 25(suppl 2):157-65 CrossRef Medline

5. Sormani M, Rio J, Tintorè $M$, et al. Scoring treatment response in patients with relapsing multiple sclerosis. Mult Scler 2013;19: 605-12 CrossRef Medline

6. Sormani MP, Signori A, Stromillo ML, et al. Refining response to treatment as defined by the Modified Rio Score. Mult Scler 2013; 19:1246-47 CrossRef Medline

7. Freedman MS, Selchen D, Arnold DL, et al. Treatment optimization in MS: Canadian MS Working Group updated recommendations. Can J Neurol Sci 2013;40:307-23 CrossRef Medline

8. Wattjes MP, Rovira À, Miller D, et al; MAGNIMS study group. Evidence-based guidelines: MAGNIMS consensus guidelines on the use of MRI in multiple sclerosis - establishing disease prognosis and monitoring patients. Nat Rev Neurol 2015;11:597-606 CrossRef Medline

9. Wiendl H, Toyka KV, Rieckmann P, et al; Multiple Sclerosis Therapy Consensus Group (MSTCG). Basic and escalating immunomodulatory treatments in multiple sclerosis: current therapeutic recommendations. J Neurol 2008;255:1449-63 CrossRef Medline

10. Coyle PK. Switching therapies in multiple sclerosis. CNS Drugs 2013;27:239-47 CrossRef Medline

11. Wattjes MP, Barkhof F. Diagnosis of natalizumab-associated progressive multifocal leukoencephalopathy using MRI. Cur Opin Neurol 2014;27:260-70 CrossRef Medline

12. Rommer PS, Zettl UK, Kieseier B, et al. Requirement for safety monitoring for approved multiple sclerosis therapies: an overview. Clin Exp Immunol 2014;175:397-407 CrossRef Medline

13. van Oosten BW, Killestein J, Barkhof F, et al. PML in a patient treated with dimethyl fumarate from a compounding pharmacy. N Engl J Med 2013;368:1658-59 CrossRef Medline

14. Arvin AM, Wolinsky JS, Kappos L, et al. Varicella-zoster virus infections in patients treated with fingolimod: risk assessment and consensus recommendations for management. JAMA Neurol 2015;72:31-39 CrossRef Medline

15. Fine AJ, Sorbello A, Kortepeter C, et al. Progressive multifocal leukoencephalopathy after natalizumab discontinuation. Ann Neurol 2014;75:108-15 CrossRef Medline

16. Wattjes MP, Killestein J. Progressive multifocal leukoencephalopathy after natalizumab discontinuation: few and true? Ann Neurol 2014;75:462 CrossRef Medline

17. Killestein J, Vennegoor A, van Golde AE, et al. PML-IRIS during fingolimod diagnosed after natalizumab discontinuation. Case Rep Neurol Med 2014;2014:307872 CrossRef Medline

18. Dubey D, Cano CA, Stüve O. Update on monitoring and adverse effects of approved second-generation disease-modifying therapies in relapsing forms of multiple sclerosis. Curr Opin Neurol 2016;29:278-85 CrossRef Medline

19. Dong-Si T, Richman S, Wattjes MP, et al. Outcome and survival of asymptomatic PML in natalizumab-treated MS patients. Ann Clin Transl Neurol 2014;1:755-64 CrossRef Medline

20. Wattjes MP, Vennegoor A, Steenwijk MD, et al. MRI pattern in asymptomatic natalizumab-associated PML. J Neurol Neurosurg Psychiatry 2015;86:793-98 CrossRef Medline

21. Wattjes MP, Vennegoor A, Mostert J, et al. Diagnosis of asymptomatic natalizumab-associated PML: are we between a rock and a hard place? J Neurol 2014;261:1139-43 CrossRef Medline

22. Richert N, Bloomgren G, Cadavid D, et al. Imaging findings for PML in natalizumab-treated MS patients. Mult Scler 2012;18(suppl 4):27. Oral 99 CrossRef

23. Phan-Ba R, Lommers E, Tshibanda L, et al. MRI preclinical detection and asymptomatic course of a progressive multifocal leucoencephalopathy (PML) under natalizumab therapy. J Neurol Neurosurg Psychiatry 2012;83:224-26 CrossRef Medline

24. Wattjes MP, Verhoeff L, Zentjens W, et al. Punctate lesion pattern suggestive of perivascular inflammation in acute natalizumabassociated progressive multifocal leukoencephalopathy: productive JC virus infection or preclinical PML-IRIS manifestation? J Neurol Neurosurg Psychiatry 2013;84:1176-77 CrossRef Medline

25. Yousry TA, Pelletier D, Cadavid D, et al. Magnetic resonance imaging pattern in natalizumab-associated progressive multifocal leukoencephalopathy. Ann Neurol 2012;72:779-87 CrossRef Medline 26. Gheuens S, Smith DR, Wang X, et al. Simultaneous PML-IRIS after 
discontinuation of natalizumab in a patient with MS. Neurology 2012;78:1390-93 CrossRef Medline

27. Hodel J, Outteryck O, Dubron C, et al. Asymptomatic progressive multifocal leukoencephalopathy associated with natalizumab: diagnostic precision with MR imaging. Radiology 2016;278:863-72 CrossRef Medline

28. Wattjes MP, Richert ND, Killestein J, et al. The chameleon of neuroinflammation: magnetic resonance imaging characteristics of natalizumab-associated progressive multifocal leukoencephalopathy. Mult Scler 2013;19:1826-40 CrossRef Medline

29. Honce JM, Nagae L, Nyberg E. Neuroimaging of natalizumab complications in multiple sclerosis: PML and other associated entities. Mult Scler Int 2015;2015:809252 CrossRef Medline

30. Kastrup O, Maschke M, Diener H, et al. Progressive multifocal leukoencephalopathy limited to the brain stem. Neuroradiology 2002;44:227-29 CrossRef Medline

31. Mathew RM, Murnane M. MRI in PML: bilateral medullary lesions. Neurology 2004;63:2380 CrossRef Medline

32. Svensson PA, Larsson EM. Infratentorial progressive multifocal leucoencephalopathy (PML) in a patient with SLE (2008: 4b). Eur Radiol 2008;18:1526-28 CrossRef Medline

33. Miyagawa $M$, Maeda $M$, Umino $M$, et al. Low signal intensity in U-fiber identified by susceptibility-weighted imaging in two cases of progressive multifocal leukoencephalopathy. J Neurol Sci 2014; 344:198-202 CrossRef Medline

34. Hodel J, Outteryck O, Verclytte S, et al. Brain magnetic susceptibility changes in patients with natalizumab-associated progressive multifocal leukoencephalopathy. AJNR Am J Neuroradiol 2015;36: 2296-302 CrossRef Medline

35. Clifford DB, De Luca A, DeLuca A, et al. Natalizumab-associated progressive multifocal leukoencephalopathy in patients with multiple sclerosis: lessons from 28 cases. Lancet Neurol 2010;9: 438-46 CrossRef Medline

36. Tan IL, McArthur JC, Clifford DB, et al. Immune reconstitution inflammatory syndrome in natalizumab-associated PML. Neurology 2011;77:1061-67 CrossRef Medline

37. Kleinschmidt-DeMasters BK, Miravalle A, Schowinsky J, et al. Update on PML and PML-IRIS occurring in multiple sclerosis patients treated with natalizumab. J Neuropathol Exp Neurol 2012;71: 604-17 CrossRef Medline

38. Miravalle A, Jensen R, Kinkel RP. Immune reconstitution inflammatory syndrome in patients with multiple sclerosis following cessation of natalizumab therapy. Arch Neurol 2011;68:186-91 CrossRef Medline

39. Wattjes MP, Wijburg MT, Vennegoor A, et al; Dutch-Belgian Natalizumab-associated PML study group. MRI characteristics of early PML-IRIS after natalizumab treatment in patients with MS. J Neurol Neurosurg Psychiatry 2016;87:879-84 CrossRef Medline

40. Wenning W, Haghikia A, Laubenberger J, et al. Treatment of progressive multifocal leukoencephalopathy associated with natalizumab. N Engl J Med 2009;361:1075-80 CrossRef Medline

41. Gheuens S, Ngo L, Wang X, et al. Metabolic profile of PML lesions in patients with and without IRIS: an observational study. Neurology 2012;79:1041-48 CrossRef Medline

42. Prosperini L, Gallo V, Petsas N, et al. One-year MRI scan predicts clinical response to interferon beta in multiple sclerosis. Eur J Neurol 2009;16:1202-09 CrossRef Medline

43. Río J, Castilló J, Rovira A, et al. Measures in the first year of therapy predict the response to interferon beta in MS. Mult Scler 2009;15: 848-53 CrossRef Medline

44. Rovira A, Auger C, Alonso J. Magnetic resonance monitoring of lesion evolution in multiple sclerosis. Ther Adv Neurol Disord 2013; 6:298-310 CrossRef Medline

45. Simon JH, Bermel RA, Rudick RA. Simple MRI metrics contribute to optimal care of the patient with multiple sclerosis. AJNR Am J Neuroradiol 2014;35:831-32 CrossRef Medline

46. Sormani MP, Bonzano L, Roccatagliata L, et al. Magnetic resonance imaging as a potential surrogate for relapses in multiple sclerosis: a meta-analytic approach. Ann Neurol 2009;65:268-75 CrossRef Medline

47. Romeo M, Martinelli V, Perego M, et al. Brain MRI activity after disease-modifying treatment may predict disability progression after 5 years in relapsing remitting multiple sclerosis patients. In: Proceedings of the 5th Joint Triennial Congress of the European and Americas Committees for Treatment and Research in Multiple Sclerosis, Amsterdam, the Netherlands. October 19-22, 2011; abstract 29

48. Río J, Nos C, Tintoré M, et al. Defining the response to interferonbeta in relapsing-remitting multiple sclerosis patients. Ann Neurol 2006;59:344-52 CrossRef Medline

49. Río J, Rovira A, Tintoré M, et al. Relationship between MRI lesion activity and response to IFN-beta in relapsing-remitting multiple sclerosis patients. Mult Scler 2008;14:479-84 CrossRef Medline

50. Rio J, Comabella M, Montalban X. Predicting responders to therapies for multiple sclerosis. Nat Rev Neurol 2009;5:553-60 CrossRef Medline

51. Tomassini V, Paolillo A, Russo P, et al. Predictors of long-term clinical response to interferon beta therapy in relapsing multiple sclerosis. J Neurol 2006;253:287-93 CrossRef Medline

52. Fisniku LK, Brex PA, Altmann DR, et al. Disability and T2 MRI lesions: a 20-year follow-up of patients with relapse onset of multiple sclerosis. Brain 2008;131:808-17 CrossRef Medline

53. Goodin DS, Traboulsee A, Knappertz V, et al; 16-Year Long Term Follow-up Study Investigators. Relationship between early clinical characteristics and long term disability outcomes: 16-year cohort study (follow-up) of the pivotal interferon $\boldsymbol{\beta}$-1b trial in multiple sclerosis. J Neurol Neurosurg Psychiatry 2012;83:282-87 CrossRef Medline

54. Bermel RA, You X, Foulds P, et al. Predictors of long-term outcome in multiple sclerosis patients treated with interferon $\boldsymbol{\beta}$. Ann Neurol 2013;73:95-103 CrossRef Medline

55. Sormani MP, Arnold DL, De Stefano N. Treatment effect on brain atrophy correlates with treatment effect on disability in multiple sclerosis. Ann Neurol 2014;75:43-49 CrossRef Medline

56. Erbayat Altay E, Fisher E, Jones SE, et al. Reliability of classifying multiple sclerosis disease activity using magnetic resonance imaging in a multiple sclerosis clinic. JAMA Neurol 2013;70:338-44 CrossRef Medline

57. Vrenken H, Jenkinson M, Horsfield MA, et al; MAGNIMS Study Group. Recommendations to improve imaging and analysis of brain lesion load and atrophy in longitudinal studies of multiple sclerosis. J Neurol 2013;260:2458-71 CrossRef Medline

58. Michel L, Larochelle C, Prat A. Update on treatments in multiple sclerosis. Presse Med 2015;44(4 pt 2):e137-51 CrossRef Medline

59. Havrdova E. Freedom from disease activity in multiple sclerosis. Neurology 2010;74(suppl 3):S3-7 CrossRef Medline

60. Giovannoni G, Turner B, Gnanapavan S, et al. Is it time to target no evident disease activity (NEDA) in multiple sclerosis? Mult Scler Rel Disord 2015;4:329-33 CrossRef Medline

61. Río J. Any evident MRI T2 lesion activity should guide change of therapy in multiple sclerosis: no. Mult Scler 2015;21:132-33 CrossRef Medline

62. Ziemssen T, Derfuss T, de Stefano N, et al. Optimizing treatment success in multiple sclerosis. J Neurol 2016;263:1053-65 CrossRef Medline

63. Dobson R, Rudick RA, Turner B, et al. Assessing treatment response to interferon- $\boldsymbol{\beta}$ : is there a role for MRI? Neurology 2014;82: 248-54 CrossRef Medline

64. Prosperini L, Fanelli F, Pozzilli C. Long-term assessment of No Evidence of Disease Activity with natalizumab in relapsing multiple sclerosis. J Neurol Sci 2016;364:145-47 CrossRef Medline

65. Coyle PK. Switching algorithms: from one immunomodulatory agent to another. J Neurol 2008;255:44-50 CrossRef Medline

66. Río J, Tintoré M, Sastre-Garriga J, et al. Change in the clinical activity of multiple sclerosis after treatment switch for suboptimal response. Eur J Neurol 2012;19:899-904 CrossRef Medline

67. De Stefano N. Assessing brain atrophy rates in a large population 
of untreated multiple sclerosis subtypes. Neurology 2010;74: 1868-76 CrossRef Medline

68. Fisher E, Lee JC, Nakamura K, et al. Gray matter atrophy in multiple sclerosis: a longitudinal study. Ann Neurol 2008;64:255-65 CrossRef Medline

69. Steenwijk MD, Daams M, Pouwels PJ, et al. What explains gray matter atrophy in long-standing multiple sclerosis? Radiology 2014;272:832-42 CrossRef Medline

70. Bergsland N, Laganà MM, Tavazzi $\mathrm{E}$, et al. Corticospinal tract integrity is related to primary motor cortex thinning in relapsing-remitting multiple sclerosis. Mult Scler 2015;21:1771-80 CrossRef Medline

71. De Stefano N, Airas L, Grigoriadis N, et al. Clinical relevance of brain volume measures in multiple sclerosis. CNS Drugs 2014;28: 147-56 CrossRef Medline

72. Vidal-Jordana A, Sastre-Garriga J, Rovira A, et al. Treating relapsing-remitting multiple sclerosis: therapy effects on brain atrophy. J Neurol 2015;262:2617-26 CrossRef Medline

73. Zivadinov R. Mechanisms of action of disease-modifying agents and brain volume changes in multiple sclerosis. Neurology 2008; 71:136-44 CrossRef Medline

74. Enzinger C, Fazekas F, Matthews PM, et al. Risk factors for progression of brain atrophy in aging: six-year follow-up of normal subjects. Neurology 2005;64:1704-11 CrossRef Medline

75. Huppertz HJ, Kröll-Seger J, Klöppel S, et al. Intra- and interscanner variability of automated voxel-based volumetry based on a 3D probabilistic atlas of human cerebral structures. Neuroimage 2010; 49:2216-24 CrossRef Medline

76. Jacobsen C, Hagemeier J, Myhr KM, et al. Brain atrophy and disability progression in multiple sclerosis patients: a 10-year follow-up study. J Neurol Neurosurg Psychiatry 2014;85:1109-15 CrossRef Medline

77. Miller DH, Soon D, Fernando KT, et al; AFFIRM Investigators. MRI outcomes in a placebo-controlled trial of natalizumab in relapsing MS. Neurology 2007;68:1390-401 CrossRef Medline

78. Radue EW, Stuart WH, Calabresi PA, et al; SENTINEL Investigators. Natalizumab plus interferon beta-1a reduces lesion formation in relapsing multiple sclerosis. J Neurol Sci 2010;292:28-35 CrossRef Medline

79. Magraner M, Coret F, Casanova B. The relationship between inflammatory activity and brain atrophy in natalizumab treated patients. Eur J Neurol 2012;81:3485-90 CrossRef

80. Radue EW, O'Connor P, Polman CH, et al; FTY720 Research Evaluating Effects of Daily Oral Therapy in Multiple Sclerosis (FREEDOMS) Study Group. Impact of fingolimod therapy on magnetic resonance imaging outcomes in patients with multiple sclerosis. Arch Neurol 2012;69:1259-69 CrossRef Medline

81. Kappos L, Traboulsee A, Constantinescu C, et al. Long-term subcutaneous interferon beta-1a therapy in patients with relapsing-remitting MS. Neurology 2006;67:944-53 CrossRef Medline

82. Goodkin DE, Vanderburg-Medendorp S, Ross JT. The effect of repositioning error on serial magnetic resonance imaging scans. Arch Neurol 1993;50:569-70 Medline

83. Tan IL, van Schijndel RA, Fazekas F, et al. Image registration and subtraction to detect active T (2) lesions in MS: an interobserver study. J Neurol 2002;249:767-73 CrossRef Medline

84. Moraal B, Meier DS, Poppe PA, et al. Subtraction MR images in a multiple sclerosis multicenter clinical trial setting. Radiology 2009; 250:506-14 CrossRef Medline

85. Moraal B, Wattjes MP, Geurts JJ, et al. Improved detection of active multiple sclerosis lesions: 3D subtraction imaging. Radiology 2010;255:154-63 CrossRef Medline

86. Battaglini M, Rossi F, Grove RA, et al. Automated identification of brain new lesions in multiple sclerosis using subtraction images. $J$ Magn Reson Imaging 2014;39:1543-49 CrossRef Medline

87. Moraal B, van den Elskamp IJ, Knol DL, et al. Long-interval T2weighted subtraction magnetic resonance imaging: a powerful new outcome measure in multiple sclerosis trials. Ann Neurol 2010;67:667-75 CrossRef Medline

88. Wattjes MP, Lutterbey GG, Gieseke J, et al. Double inversion recovery brain imaging at 3T: diagnostic value in the detection of multiple sclerosis lesions. AJNR Am J Neuroradiol 2007;28:54-59 Medline

89. Sethi V, Yousry TA, Muhlert N, et al. Improved detection of cortical MS lesions with phase-sensitive inversion recovery MRI. J Neurol Neurosurg Psychiatry 2012;83:877-82 CrossRef Medline

90. de Kouchkovsky I, Fieremans E, Fleysher L, et al. Quantification of normal-appearing white matter tract integrity in multiple sclerosis: a diffusion kurtosis imaging study. J Neurol 2016;263: 1146-55 CrossRef Medline

91. Testaverde L, Caporali L, Venditti E, et al. Diffusion tensor imaging applications in multiple sclerosis patients using $3 \mathrm{~T}$ magnetic resonance: a preliminary study. Eur Radiol 2012;22:990-97 CrossRef Medline

92. Klawiter EC. Current and new directions in MRI in multiple sclerosis. Continuum (Minneap Minn) 2013;19(4 multiple sclerosis): 1058-73 CrossRef Medline

93. Naismith RT. Increased diffusivity in acute multiple sclerosis lesions predicts risk of black hole. Neurology 2010;74:1694-701 CrossRef Medline

94. Fox RJ, Sakaie K, Lee JC, et al. A validation study of multicenter diffusion tensor imaging: reliability of fractional anisotropy and diffusivity values. AJNR Am J Neuroradiol 2012;33:695-700 CrossRef Medline

95. Werring DJ, Brassat D, Droogan AG, et al. The pathogenesis of lesions and normal-appearing white matter changes in multiple sclerosis: a serial diffusion MRI study. Brain 2000;123(pt 8): 1667-76 CrossRef Medline

96. Rovira A, León A. MR in the diagnosis and monitoring of multiple sclerosis: an overview. Eur J Radiol 2008;67:409-14 CrossRef Medline

97. Chen JT, Collins DL, Atkins HL, et al; Canadian MS/BMT Study Group. Magnetization transfer ratio evolution with demyelination and remyelination in multiple sclerosis lesions. Ann Neurol 2008;63:254-62 CrossRef Medline

98. van den Elskamp IJ, Knol DL, Vrenken H, et al. Lesional magnetization transfer ratio: a feasible outcome for remyelinating treatment trials in multiple sclerosis. Mult Scler 2010;16:660-69 CrossRef Medline

99. Simon B, Schmidt S, Lukas C, et al. Improved in vivo detection of cortical lesions in multiple sclerosis using double inversion recovery MR imaging at 3 Tesla. Eur Radiol 2010;20:1675-83 CrossRef Medline

100. Nelson F, Poonawalla AH, Hou P, et al. Improved identification of intracortical lesions in multiple sclerosis with phase-sensitive inversion recovery in combination with fast double inversion recovery $M R$ imaging. AJNR Am J Neuroradiol 2007;28:1645-49 CrossRef Medline

101. Geurts JJ, Pouwels PJ, Uitdehaag BM, et al. Intracortical lesions in multiple sclerosis: improved detection with 3D double inversion-recovery MR imaging. Radiology 2005;236:254-60 CrossRef Medline

102. Hagiwara A, Hori M, Yokoyama K, et al. Synthetic MRI in the detection of multiple sclerosis plaques. AJNR Am J Neuroradiol 2016 Dec 8. [Epub ahead of print] CrossRef Medline

103. Calabrese M, Rinaldi F, Seppi D, et al. Cortical diffusion-tensor imaging abnormalities in multiple sclerosis: a 3-year longitudinal study. Radiology 2011;261:891-98 CrossRef Medline 